\title{
Increased Guanylate Cyclase Activity Is Associated with an Increase in Cyclic Guanosine 3',5'-monophosphate in Left Ventricular Hypertrophy
}

\author{
J.D. Sadoff, ${ }^{\star}$ P.M. Scholz, ${ }^{\star}$ J. Tse, ${ }^{\ddagger}$ and H.R. Weiss ${ }^{\S}$ \\ Departments of *Surgery, ${ }^{\ddagger}$ Anesthesia, and ${ }^{\S}$ Physiology \& Biophysics, Heart and Brain Circulation Laboratory, University of Medicine \\ and Dentistry of New Jersey, Robert Wood Johnson Medical School, New Brunswick, New Jersey 08903-0019
}

\begin{abstract}
Left ventricular hypertrophy (LVH) produced by aortic valve plication leads to increased myocardial cyclic GMP. We tested whether this was a result of increased soluble guanylate cyclase activity or nitric oxide (NO) synthase and its functional consequences. We used the nitric oxide donor 3-morpholino-sydnonimine (SIN-1) or the NO synthase inhibitor $N^{\mathrm{G}}$-nitro-l-arginine methyl ester (L-NAME) in 12 control and $12 \mathrm{LVH}$ anesthetized open-chest mongrel dogs. L-NAME (6 mg/kg) or SIN-1 (1 $\mu \mathrm{g} / \mathrm{kg}$ per min) was infused into the left anterior descending coronary artery and regional segment work and cyclic GMP levels were determined. In vitro myocardial guanylate cyclase sensitivity $\left(0.43 \pm 0.04\right.$ to $\left.0.28 \pm 0.04 \mathrm{mM}\left[\mathrm{EC}_{50}\right]\right)$ and maximal activity $(10.1 \pm 2.9$ to $25.5 \pm 6.5 \mathrm{pmol} / \mathrm{mg}$ protein per $\mathrm{min})$ were significantly increased in LVH as compared with control animals in response to nitroprusside stimulation, but cyclic GMP-phosphodiesterase activity was similar. In LVH dogs, basal cyclic GMP was significantly elevated in vivo when compared with controls. Treatment of dogs with SIN-1 resulted in a significant increase in cyclic GMP in control $(1.09 \pm 0.12$ to $1.48 \pm 0.19 \mathrm{pmol} / \mathrm{gram})$ and a greater increase in the $\mathrm{LVH}$ group $(1.78 \pm 0.16$ to $3.58 \pm 0.71 \mathrm{pmol} / \mathrm{g})$. L-NAME had no effect on myocardial cyclic GMP levels in control or LVH dogs. Segment work decreased in the control group after SIN-1 (1,573 \pm 290 to $855 \pm 211$ grams $\times \mathrm{mm} / \mathrm{min})$. $\mathrm{LVH}$ dogs showed no decrement in work as a result of treatment with SIN-1. L-NAME did not cause significant changes in myocardial cyclic GMP, $\mathrm{O}_{2}$ consumption, or work in either control or LVH dogs, but vascular effects were evident. SIN-1 increased cyclic GMP, and with greater effect on LVH; however, this resulted in a decrement in function only in the control group. The greater increased cyclic GMP in LVH dogs is not related to increased NO production, but is related to significantly higher sensitivity and maximal activity of soluble myocardial guanylate cyclase. (J. Clin. Invest. 1996. 98:838-845.) Key words: myocardial work • myocardial $\mathrm{O}_{2}$ consumption - coronary blood flow • aortic valve stenosis $\bullet \operatorname{dog}$
\end{abstract}

Address correspondence to Peter M. Scholz, Department of Surgery, UMDNJ-Robert Wood Johnson Medical School, One Robert Wood Johnson Place, CN-19, New Brunswick, NJ 08903-0019. Phone: 908235-7642; FAX: 908-235-7013.

Received for publication 7 November 1995 and accepted in revised form 23 May 1996.

J. Clin. Invest.

(c) The American Society for Clinical Investigation, Inc. 0021-9738/96/08/0838/08 \$2.00

Volume 98, Number 3, August 1996, 838-845

\section{Introduction}

Changes in the myocardial level of the second messenger cyclic GMP exert both metabolic and inotropic effects on the heart (1-3). It causes negative myocardial metabolic, inotropic, and functional effects, through reductions in cytosolic calcium $(1,3,4)$. These effects have been long known both in vivo and in vitro in a variety of species including humans $(1,2,5,6)$. Previous studies from our laboratory also indicate that stimulation of the cyclic GMP pathway results in decreased states of myocardial metabolism or function (2, 7-9). In vascular smooth muscle, increases in cyclic GMP levels induce vasodilation (3, 10). The mechanisms linking the myocardial level of cyclic GMP and myocardial function have not been fully delineated.

The production of cyclic GMP is controlled by guanylate cyclase and alterations in the amount or activity of this enzyme alter cyclic GMP and myocardial function $(1,10,11)$. Cyclic GMP production can be stimulated through the action of several systems, e.g., the nitric oxide $(\mathrm{NO}),{ }^{1}$ cholinergic, or atrial natriuretic pathways $(1,10,11)$. In vascular smooth muscle, the nitric oxide system is a major controller of cyclic GMP (12). The importance of endogenous NO in the control of myocardial cyclic GMP has been questioned $(13,14)$, although it can reduce myocyte contractility (15). Stimulation of guanylate cyclase leads to vascular smooth muscle relaxation and vasodilatation $(10,15,16)$.

Myocardial cyclic GMP levels have been reported to be elevated in some types of pressure-load hypertrophy $(2,17)$. Cyclic GMP levels may also increase during some forms of heart failure $(18,19)$. In experimental left ventricular hypertrophy produced by aortic valve plication, we have observed significantly elevated basal levels of cyclic GMP compared with control hearts $(2,7)$. Cyclic GMP responses to stimulation also appear enhanced (2). The functional and metabolic consequences of cyclic GMP appear to be altered in cardiac hypertrophy (2, 9). The reasons for this elevated cyclic GMP have not been determined.

The present study was designed to test whether the increased myocardial cyclic GMP seen in left ventricular hypertrophy was related to elevated guanylate cyclase activity or increased nitric oxide synthase activity and the functional consequence of this elevated cyclic GMP. We also compared cyclic GMP-phosphodiesterase activity in control and hypertrophied dog hearts. It is known that the arginine analog $N^{\mathrm{G}}$ nitro-L-arginine methyl ester (L-NAME) is a potent inhibitor of nitric oxide production $(12,15,20)$. The nitric oxide donor/ guanylate cyclase stimulator 3-morpholino-sydnonimine (SIN-1)

1. Abbreviations used in this paper: $\mathrm{Cfx}$, circumflex; $\mathrm{dP} / \mathrm{dt}_{\max }$, first derivative of left ventricular pressure; L-NAME, $N^{\mathrm{G}}$-nitro-L-arginine methyl ester; LAD, left anterior descending coronary artery; NO, nitric oxide; SIN-1, 3-morpholino-sydnonimine. 
was also used in both control and left ventricular hypertrophic animals. SIN-1 is the active metabolite of molsidomine, which spontaneously decomposes in solution to release $\mathrm{NO}(21)$. We injected these agents into the left anterior descending coronary (LAD) artery while the region perfused by the circumflex coronary (CFX) artery was used as a functional control in hypertrophied and nonhypertrophied dogs.

\section{Methods}

This study was performed in 24 adult mongrel dogs of either sex that weighed between 21 and $29 \mathrm{~kg}$. In 12 of these animals, pressure overload left ventricular hypertrophy was created using aortic valve plication (22-24). Dogs were 8-10 wk of age and weighed 4-7 kg at the time of plication. They were anesthetized with intravenous sodium thiamylal $(25 \mathrm{mg} / \mathrm{kg})$, intubated, and maintained on $0.5-1.0 \%$ halothane and a 50/50 nitrous oxide and oxygen mixture. Percutaneous catheters were placed in a femoral artery and used for direct arterial pressure measurements. Limb electrodes were used for electrocardiogram (EKG) monitoring. The heart was exposed through a sterile right thoracotomy and the noncoronary sinus of Valsalva was plicated with a single horizontal mattress stitch of nonabsorbable suture reinforced by teflon felt pledgets. A palpable thrill was noted in the ascending aorta after the plication. Presence of a thrill has been shown to correlate with at least a $15-\mathrm{mmHg}$ gradient, which is sufficient to produce significant left ventricular hypertrophy after 6 mo. The thoracotomy was then closed over a temporary chest tube. All experiments were conducted in accordance with the Guide for the Care of Laboratory Animals (DHHS Publication No. 85-23, revised 1985) and were approved by our Institutional Animal Care and Use Committee.

Approximately 6 mo after the aortic valve plication, 12 left ventricular hypertrophy animals were compared with 12 age-matched mongrel control dogs. The animals were anesthetized with intravenous sodium pentobarbital $(30 \mathrm{mg} / \mathrm{kg})$, tracheally intubated, and ventilated with a volume ventilator. Additional pentobarbital $(60 \mathrm{mg})$ was administered as required. Arterial blood gases and $\mathrm{O}_{2}$ saturation were maintained at physiological ranges throughout the experiment by controlling respiratory rate, tidal volume, and $\mathrm{F}_{\mathrm{i}} \mathrm{O}_{2}$. These were monitored periodically using arterial blood samples analyzed for $\mathrm{pH}$, $\mathrm{Po}_{2}$ and $\mathrm{Pco}_{2}$ on a Radiometer ABL30 blood gas analyzer. Hemoglobin concentration and $\mathrm{O}_{2}$ saturation were measured using a Radiometer OSM2 hemoximeter.

Limb electrodes were placed for electrocardiographic monitoring. A 20-gauge angiocatheter was inserted percutaneously into a peripheral vein for administration of fluid and anesthetic. A polyethylene catheter was introduced into the right femoral vein. The left femoral artery was cannulated for arterial blood samples. Micromanometers (Millar MPC500, Houston, TX) were introduced into the left ventricle through an apical stab wound and through the right femoral artery into the ascending aorta. These were used to measure left ventricular and aortic blood pressures, respectively. The heart was exposed through a left thoracotomy at the fifth intercostal space.

The left anterior descending coronary artery (LAD) and its first or second diagonal branch were exposed. An ultrasonic flow probe (Transonic Systems, Inc., Ithaca, NY) was placed around the LAD just distal to the second diagonal branch. The diagonal branch was cannulated and used for injection of a nitric oxide synthase inhibitor, a nitric oxide donor/guanylate cyclase stimulator, and Evans blue dye. In addition, a left anterior descending coronary vein was cannulated for venous blood sampling. Ultrasonic dimension crystals (5 $\mathrm{mHz}$; Triton sonomicrometer, Tech, San Diego, CA) were inserted to a depth of 4-6 mm and $\sim 1 \mathrm{~cm}$ apart on the anterior surface of the left ventricle supplied by the LAD. The position of the crystals was midway between the base and apex, in the short axis of the heart. Miniature force gauges (Warren Research Products, Charleston, SC) were sewn into the myocardium just adjacent to the length crystals in the area supplied by the LAD and on the posterolateral surface of the heart supplied by the CFX branch of the left coronary artery. The force gauges were placed in the short axis of the heart, in series with the length crystals at a depth of 4-6 mm. The force transducers were connected to a Wheatstone bridge balanced and calibrated before the experiment.

Lead II EKG, global hemodynamics (left ventricular and aortic pressures), and regional functional measurements (segment length and force) were continuously monitored on a multichannel digital electrostatic recorder (ES1000; Gould Inc., Cleveland, OH). The signals were simultaneously digitized at a sampling frequency of $200 \mathrm{~Hz}$ over 10-s intervals (Data Translation DT2801) and acquired on a computer for analysis. The digitized data were analyzed using the algorithm of ensemble averaging of all consecutive heart beats. The parameters measured were: heart rate, aortic blood pressure, left ventricular pressure, segment force, and length. The parameters calculated were: the first derivative of the left ventricular pressure $\left(\mathrm{dP} / \mathrm{dt}_{\max }\right)$, peak force, percent segment shortening, and total regional myocardial segment work. Regional myocardial segment work was calculated by determining the area under the force-length loop during the averaged heart beat.

Regional myocardial $\mathrm{O}_{2}$ consumption was calculated using the Fick principle from blood flow (ultrasonic transducer), $\mathrm{O}_{2}$ extraction, arterial, and venous $\mathrm{O}_{2}$ saturations and hemoglobin data (blood samples) from the LAD region. The area of blood flow distribution was confirmed at the end of the experiment by injecting Evans blue dye into the LAD. Blood flows were normalized and expressed per unit weight.

The animals were allowed to stabilize for $\sim 15 \mathrm{~min}$. Baseline physiologic and blood gas measurements were then recorded. Biopsies were taken from LAD and CFX regions (stored in liquid nitrogen), and repeat physiologic and blood gas measurements were obtained. Either the nitric oxide synthase inhibitor L-NAME or the NO donor/guanylate cyclase stimulator SIN-1 were infused into the LAD artery via the cannulated LAD diagonal branch over 2 min or 7-10 min, respectively (L-NAME $6 \mathrm{mg} / \mathrm{kg}$, SIN-1 $1 \mu \mathrm{g} / \mathrm{kg}$ per min). The dose of L-NAME was chosen that prevented a significant vasodilation to acetylcholine. The dose of SIN-1 was selected that produced a significant decrement in local force development with limited peripheral effects. The CFX artery region served as a functional control. After infusion of one of these agents, repeat physiologic and blood gas measurements were obtained. Evans blue dye was injected into the cannulated diagonal branch of the LAD and the heart was rapidly excised at the atrioventricular ring. The heart was frozen in liquid nitrogen and then weighed.

Transmural biopsies were taken from the LAD and CFX regions using a high speed suction biopsy drill (Alko Diagnostics, Holliston, MA) to determine cyclic GMP levels. The drill excises a $3.5-\mathrm{mm}$ plug and freezes it immediately in methyl butane cooled by liquid nitrogen. The heart was excised at the end of each experiment and frozen in liquid nitrogen for later analysis. The biopsy and heart samples were later warmed to $\mathrm{O}^{\circ} \mathrm{C}$ and homogenized in ethanol using a Brinkmann Polytron placed in an ice bath. The homogenate was centrifuged at 30,000 $\mathrm{g}$ for $15 \mathrm{~min}$ in a Sorvall RC-5B (Wilmington, DE) centrifuge. The supernatant was recovered. The pellet was resuspended in $1 \mathrm{ml}$ of 2:1 ethanol/water and centrifuged as before. The combined supernatants were evaporated to dryness in a $60^{\circ} \mathrm{C}$ bath under a stream of nitrogen gas. The final residue was dissolved in 1.5 $\mathrm{ml}$ of assay buffer $(0.05 \mathrm{~mol} /$ liter sodium acetate, $\mathrm{pH} 5.8$, containing sodium azide). Cyclic GMP levels were determined using a radioimmunoassay (Amersham Corp., Arlington Heights, IL). This assay measures the competitive binding of ${ }^{125}$ I-cyclic GMP to a cyclic GMP specific antibody. After construction of a standard curve, cyclic GMP levels were determined directly from the counts in picomoles/gram of tissue wet weight.

Soluble guanylate cyclase activity (25) was determined from a transmural sample obtained from the CFX region. The tissue was homogenized with 10 volumes of ice-cold homogenization buffer (con- 
taining $0.25 \mathrm{M}$ sucrose, $5 \mathrm{mM}$ Tris- $\mathrm{HCl}$ [Fisher Scientific, Fair Lawn, $\mathrm{NJ}$ ], pH 7.4 and $1 \mathrm{mM} \mathrm{MgCl}$ ), using a Brinkmann Polytron homogenizer (three bursts of $5 \mathrm{~s}$ at maximum speed). The sample was then centrifuged at $1,000 \mathrm{~g}$ for $10 \mathrm{~min}$ at $4^{\circ} \mathrm{C}$. The supernatant was removed and centrifuged at $45,000 \mathrm{~g}$ at $4^{\circ} \mathrm{C}$ for $25 \mathrm{~min}$. The supernatant was used as the source of soluble enzyme preparation. This guanylate cyclase assay is the modification of Kimura et al. (26). The standard assay contains in a volume of $0.2 \mathrm{ml}: 50 \mathrm{mM}$ Tris- $\mathrm{HCl}$ (pH 7.6), 10 $\mathrm{mM}$ theophylline (Sigma Chemical Co., St. Louis, MO), a GTP regenerating system consisting of $10 \mathrm{mM}$ creatine phosphate (Sigma Chemical Co.), and $10 \mu \mathrm{g}$ creatine phosphokinase (200 U/mg protein [Sigma Chemical Co.], $4 \mathrm{mM} \mathrm{MgCl}, 1 \mathrm{mM} \mathrm{GTP}$, in the absence or presence of nitroprusside $(0.1,0.3,0.5,1$, and $3 \mathrm{mM}$ [Sigma Chemical Co.]). Reactions were initiated by the addition of the enzyme preparation and incubated for $10 \mathrm{~min}$ at $37^{\circ} \mathrm{C}$. Reactions were terminated by the addition of $0.8 \mathrm{ml}$ of $50 \mathrm{mM}$ sodium acetate $(\mathrm{pH} 4.0)$ followed by heating at $90^{\circ} \mathrm{C}$ for $3 \mathrm{~min}$. Measurements were obtained for maximal activity at the plateau of nitroprusside stimulation $\left(\mathrm{V}_{\max } ; \mathrm{pmol} /\right.$ $\mathrm{mg}$ protein per $\mathrm{min}$ ) and sensitivity $\left(\mathrm{EC}_{50} ; \mathrm{mM}\right)$ of guanylate cyclase from individual dose-response curves.

The assay method for cyclic GMP-phosphodiesterase activity was a modification of Tse et al. (27). The general reaction sequence involved the conversion of radioactive cyclic GMP by phosphodiesterase to 5'-GMP. The 5'-nucleotide was then hydrolyzed to guanosine by a $5^{\prime}$-nucleotidase present in snake venom. Myocardial tissue $(0.4 \mathrm{gm})$ from 10 control and $10 \mathrm{LVH}$ dogs was homogenized with 10 vol of ice-cold $50 \mathrm{mM}$ Tris- $\mathrm{HCl}$ buffer ( $\mathrm{pH}$ 7.5) containing 3 $\mathrm{mM}$ 2-mercaptoethanol, using a Brinkmann Polytron homogenizer (30 s at maximum speed). The homogenate was centrifuged at $4^{\circ} \mathrm{C}$ for $20 \mathrm{~min}$ at $30,000 \mathrm{~g}$ and the supernatant was used as the source of soluble enzymes. The standard assay system for low Km cyclic-GMP phosphodiesterase contained, in a volume of $0.2 \mathrm{ml}, 50 \mathrm{mM}$ Tris- $\mathrm{HCl}$ buffer ( $\mathrm{pH} 8.0$ ), $5 \mathrm{mM} \mathrm{MgCl}_{2}, 40 \mu \mathrm{g}$ snake venom, $0.4 \mu \mathrm{M}\left[{ }^{3} \mathrm{H}\right]$ cyclic GMP, and an appropriate amount of enzyme preparations $(2-4 \mu \mathrm{g}$ protein). The assays were carried out in the absence and the presence of the specific cyclic GMP-phosphodiesterase inhibitor, zaprinast $(100 \mu \mathrm{M})$. Reactions were initiated with addition of the enzyme preparation and carried out at $37^{\circ} \mathrm{C}$ for $10 \mathrm{~min}$. The reactions were terminated by heating the reaction mixtures at $90^{\circ} \mathrm{C}$ for $1 \mathrm{~min}$, and $0.3 \mathrm{ml}$ of water was then added to the incubation tube. The reaction mixtures were applied onto AG1-X8 columns $\left(\mathrm{Cl}^{-}\right.$form, $\left.0.5 \times 1.0 \mathrm{~cm}\right)$, and the eluates were collected. $\left[{ }^{3} \mathrm{H}\right]$ Guanosine was eluted with an additional $4.5 \mathrm{ml}$ of $1 \mathrm{mM} \mathrm{HCl}$. The combined eluates were counted in $10 \mathrm{ml}$ of scintillation fluid. The assay was performed in triplicate. Protein concentration was measured using a protein assay (Bio-Rad Laboratories, Richmond, VA). The units of low $\mathrm{K}_{\mathrm{m}}$ cyclic GMP-phosphodiesterase activity were expressed as picomoles of cyclic nucleotide hydrolyzed/mg protein per min. The specific cyclic GMPphosphodiesterase activity was defined as the difference between the total activity and the nonspecific activity in the presence of zaprinast.

A repeated measure ANOVA was used to compare variables measured in the experimental and control regions before and during treatment. Analysis was made to determine if there were differences within a region in response to the treatment, or between regions in each experimental stage. A $P$ value of $<0.05$ was accepted as significant. All values are expressed as mean \pm SEM.

\section{Results}

The effects of intracoronary infusions of SIN-1 and L-NAME on global hemodynamics in anesthetized control and left ventricular hypertrophic dogs are summarized in Table I. Under baseline conditions, there was a pressure gradient between peak left ventricular pressure and systolic arterial blood pressure of $44 \pm 6 \mathrm{mmHg}$ in the left ventricular hypertrophy groups. Left ventricular pressure was significantly higher in left ven-
Table I. Effects of Intracoronary SIN-1 or L-NAME on Global Hemodynamics in Control and Left Ventricular Hypertrophic Dogs

\begin{tabular}{lcccc}
\hline & \multicolumn{2}{c}{ Control } & \multicolumn{2}{c}{ LVH } \\
\hline & Baseline & SIN-1 & Baseline & SIN-1 \\
HR (bpm) & $175 \pm 7$ & $169 \pm 9$ & $161 \pm 5$ & $163 \pm 5$ \\
SBP (mmHg) & $132 \pm 6$ & $102 \pm 9^{*}$ & $117 \pm 7$ & $109 \pm 7$ \\
DBP (mmHg) & $100 \pm 7$ & $78 \pm 8$ & $90 \pm 6$ & $86 \pm 5$ \\
Mean BP (mmHg) & $113 \pm 7$ & $88 \pm 9^{*}$ & $101 \pm 6$ & $96 \pm 5$ \\
LV SBP (mmHg) & $134 \pm 5$ & $109 \pm 8^{*}$ & $152 \pm 5^{\ddagger}$ & $145 \pm 7^{\ddagger}$ \\
LV dP/dt & & & & \\
$\quad(\mathrm{mmHg}$ & & & & \\
& $3,482 \pm 487$ & $2,719 \pm 488$ & $3,108 \pm 348$ & $3,167 \pm 261$ \\
HR (bpm) & Baseline & L-NAME & Baseline & L-NAME \\
SBP (mmHg) & $161 \pm 5$ & $160 \pm 5$ & $147 \pm 7$ & $150 \pm 6$ \\
DBP (mmHg) & $115 \pm 7$ & $122 \pm 8$ & $116 \pm 6$ & $126 \pm 5$ \\
Mean BP (mmHg) & $93 \pm 6$ & $96 \pm 7$ & $89 \pm 7$ & $99 \pm 6$ \\
LV SBP (mmHg) & $111 \pm 5$ & $107 \pm 9$ & $100 \pm 6$ & $108 \pm 5$ \\
LV dP/dt & $121 \pm 8$ & $162 \pm 13^{\ddagger}$ & $160 \pm 12^{\ddagger}$ \\
$\quad(\mathrm{mmHg} / \mathrm{s})$ & $2,162 \pm 159$ & $2,135 \pm 197$ & $2,827 \pm 345$ & $2,933 \pm 437$ \\
& & & & \\
\end{tabular}

Values are expressed as mean \pm SEM. *Different from baseline; ${ }^{\text {differ- }}$ ent from control group. HR, heart rate; SBP, systolic blood pressure; DBP, diastolic blood pressure; LV, left ventricular.

tricular hypertrophic groups than in controls. SIN-1 caused significant vasodilation in the control group as shown in Table I. In left ventricular hypertrophy and control groups, intracoronary infusion of L-NAME had no significant effects on heart rate, systolic blood pressure, diastolic blood pressure, mean blood pressure, left ventricular pressure, or left ventricular $\mathrm{dP} /$ $\mathrm{dt}_{\max }$. In the dogs with left ventricular hypertrophy, the heart weight/body weight ratio was significantly higher than that of the control group $(10.63 \pm 0.97$ vs $6.89 \pm 0.24$ grams $/ \mathrm{kg})$.

To test the effectiveness of nitric oxide synthase blockade, acetylcholine was injected as a $1-\mu \mathrm{g}$ bolus via the LAD diagonal branch catheter both before and after L-NAME. Before blockade, acetylcholine caused a significant twofold increase in LAD blood flow $(+18.8 \pm 1.9 \mathrm{ml} / \mathrm{min})$ in both controls and $(+24.2 \pm 5.3 \mathrm{ml} / \mathrm{min})$ in left ventricular hypertrophic animals. After L-NAME was infused, LAD blood flow was not significantly increased following the bolus of acetylcholine $(+3.5 \pm 1.3$ $\mathrm{ml} / \mathrm{min}$ for controls and $+4.8 \pm 1.3 \mathrm{ml} / \mathrm{min}$ in left ventricular hypertrophy dogs).

The effects of intracoronary SIN-1 or L-NAME on regional myocardial function are reported in Table II. In animals receiving SIN-1, there was a decrease in peak force in the LAD but not the CFX region. The decrease in LAD percentage shortening was not significant. During the infusion of SIN-1, there was a significant decrease in segment work, but this was seen in control dogs only (Fig. 1, top). In the left ventricular hypertrophy group, SIN-1 had no significant effects on regional myocardial mechanics. LAD segment force and percentage shortening were unchanged in both control and left ventricular hypertrophic dogs after L-NAME; leading to no net change in segment work (Fig. 1, bottom). The circumflex (CFX) control region had no change in segment force (control or left ventricular hypertrophy) due to intracoronary infusion of L-NAME or SIN-1. 
Table II. Effects of Intracoronary SIN-1 or L-NAME on Regional Myocardial Mechanics in Control and Left Ventricular Hypertrophic Dogs

\begin{tabular}{lcccc}
\hline & \multicolumn{2}{c}{ Control } & \multicolumn{2}{c}{ LVH } \\
\hline & Baseline & SIN-1 & Baseline & SIN-1 \\
LAD (experimental) & & & & \\
$\quad \begin{array}{l}\text { Peak force (g) } \\
\text { Percent shortening }\end{array}$ & $10.3 \pm 0.6$ & $8.4 \pm 0.7^{*}$ & $11.2 \pm 1.4$ & $10.9 \pm 1.3$ \\
$\quad \begin{array}{l}\text { End diastolic } \\
\text { length (mm) }\end{array}$ & $11.9 \pm 0.9$ & $11.9 \pm 0.6$ & $11.1 \pm 0.4$ & $11.1 \pm 0.4$ \\
CFX (control) & & & & \\
Peak force (g) & $10.3 \pm 1.1$ & $9.3 \pm 0.3$ & $8.0 \pm 1.2$ & $7.8 \pm 1.4$ \\
& & & & \\
& & & & \\
& Baseline & L-NAME & Baseline & L-NAME \\
LAD (experimental) & & & & \\
$\quad \begin{array}{l}\text { Peak force (g) } \\
\text { Percent shortening }\end{array}$ & $11.5 \pm 1.2$ & $10.8 \pm 1.6$ & $10.3 \pm 0.3$ & $10.3 \pm 0.4$ \\
End diastolic & $11.6 \pm 3.1$ & $10.9 \pm 2.3$ & $10.3 \pm 2.3$ & $9.4 \pm 2.2$ \\
$\quad$ length (mm) & $12.8 \pm 1.2$ & $11.9 \pm 1.0$ & $8.7 \pm 0.6^{\ddagger}$ & $8.7 \pm 0.6^{\ddagger}$ \\
CFX (control) & & & & \\
$\quad$ Peak force (g) & $10.6 \pm 1.7$ & $10.8 \pm 1.3$ & $8.1 \pm 2.3$ & $9.8 \pm 2.4$
\end{tabular}

Values are expressed as mean \pm SEM. *Different from baseline; ${ }^{*}$ different from control group.

Table III summarizes the effects of SIN-1 or L-NAME on coronary blood flow, myocardial venous $\mathrm{O}_{2}$ saturation, and myocardial $\mathrm{O}_{2}$ extraction. SIN-1 caused LAD blood flow to significantly decrease to $75 \%$ of the pre-SIN-1 value in controls, but flow was not significantly changed in left ventricular hypertrophy. Local $\mathrm{O}_{2}$ extraction significantly increased in control dogs, but was not significantly changed in left ventricular hypertrophy after $\mathrm{SIN}-1$. Local myocardial $\mathrm{O}_{2}$ consumption remained unchanged in both groups after SIN-1, although in controls, there was a downward trend (Fig. 2, top). In all left ventricular hypertrophy dogs, baseline myocardial $\mathrm{O}_{2}$ consumption was significantly elevated compared to controls. L-NAME caused local vasoconstriction in control but not left ventricular hypertrophy animals: LAD blood flow significantly
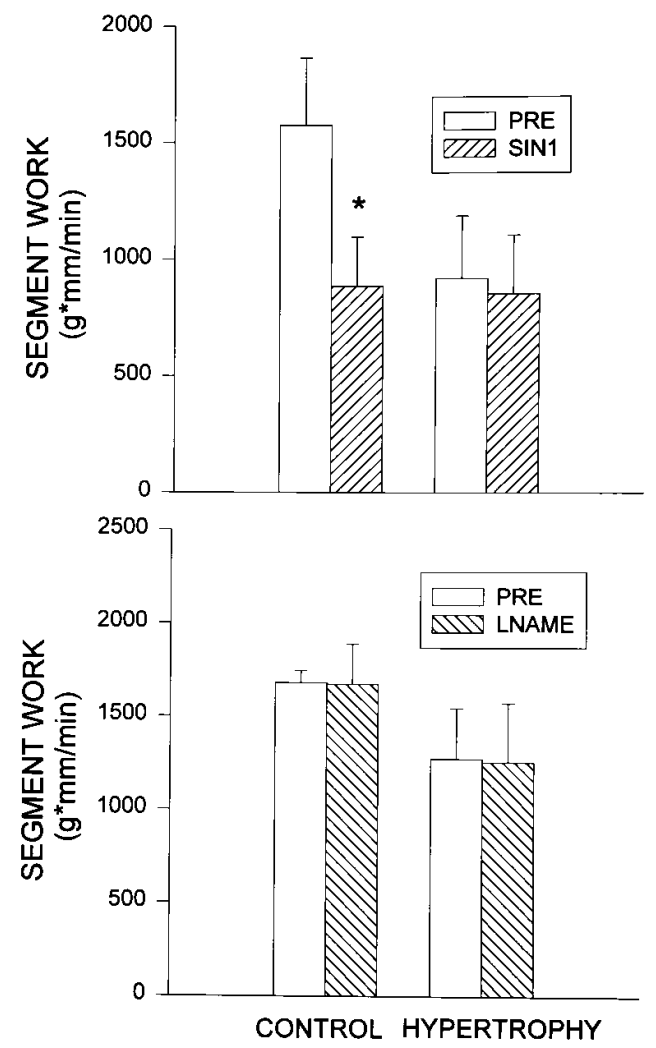

Figure 1. Effect of SIN-1 (top) and L-NAME (bottom) on segment work of the LAD region of the left ventricular free wall of both control and aortic valve stenosis-induced cardiac hypertrophic dogs. *Significantly different from control (PRE) period.

decreased to $86 \%$ of the pre-L-NAME value in controls and $90 \%$ in the left ventricular hypertrophy dogs. Local myocardial $\mathrm{O}_{2}$ extraction significantly increased by $17 \%$ in controls and nonsignificantly by $12 \%$ in left ventricular hypertrophy dogs. In control and left ventricular hypertrophy dogs, local myocardial $\mathrm{O}_{2}$ consumption remained unchanged after L-NAME (Fig. 2, bottom).

Table III. Effects of Intracoronoary SIN-1 or L-NAME on Regional Myocardial Oxygenation in Control and Left Ventricular Hypertrophic Dogs

\begin{tabular}{|c|c|c|c|c|}
\hline & \multicolumn{2}{|c|}{ Control } & \multicolumn{2}{|c|}{ LVH } \\
\hline & Baseline & SIN-1 & Baseline & SIN-1 \\
\hline Venous $\mathrm{O}_{2}$ saturation (\%) & $49 \pm 4$ & $44 \pm 4^{*}$ & $37 \pm 2^{\ddagger}$ & $34 \pm 2^{\ddagger}$ \\
\hline $\begin{array}{l}\text { LAD flow } \\
(\mathrm{ml} / \mathrm{min} \text { per } 100 \text { grams })\end{array}$ & $66.5 \pm 8.5$ & $50.1 \pm 10.2^{*}$ & $81.9 \pm 7.8$ & $81.1 \pm 10.4$ \\
\hline $\begin{array}{l}\mathrm{O}_{2} \text { extraction } \\
\quad\left(\mathrm{ml} \mathrm{O}_{2} / 100 \mathrm{ml}\right)\end{array}$ & $10.3 \pm 1.1$ & $11.5 \pm 1.0^{*}$ & $12.2 \pm 0.6$ & $12.7 \pm 0.7$ \\
\hline Venous $\mathrm{O}_{2}$ saturation (\%) & $\begin{array}{c}\text { Baseline } \\
56 \pm 5\end{array}$ & $\begin{array}{l}\text { L-NAME } \\
50 \pm 5^{*}\end{array}$ & $\begin{array}{c}\text { Baseline } \\
42 \pm 5\end{array}$ & $\begin{array}{l}\text { L-NAME } \\
\quad 37 \pm 4^{*}\end{array}$ \\
\hline $\begin{array}{l}\text { LAD flow } \\
\text { (ml/min per } 100 \text { grams })\end{array}$ & $87.6 \pm 9.3$ & $75.7 \pm 11.1 *$ & $102.3 \pm 20.3$ & $92.5 \pm 19.4^{*}$ \\
\hline $\begin{array}{l}\mathrm{O}_{2} \text { extraction } \\
\quad\left(\mathrm{ml} \mathrm{O}_{2} / 100 \mathrm{ml}\right)\end{array}$ & $8.9 \pm 0.9$ & $10.4 \pm 1.1^{*}$ & $10.8 \pm 0.4$ & $12.1 \pm 0.6$ \\
\hline
\end{tabular}

Values are expressed as mean \pm SEM. *Different from baseline; ${ }^{\ddagger}$ different from control group. 

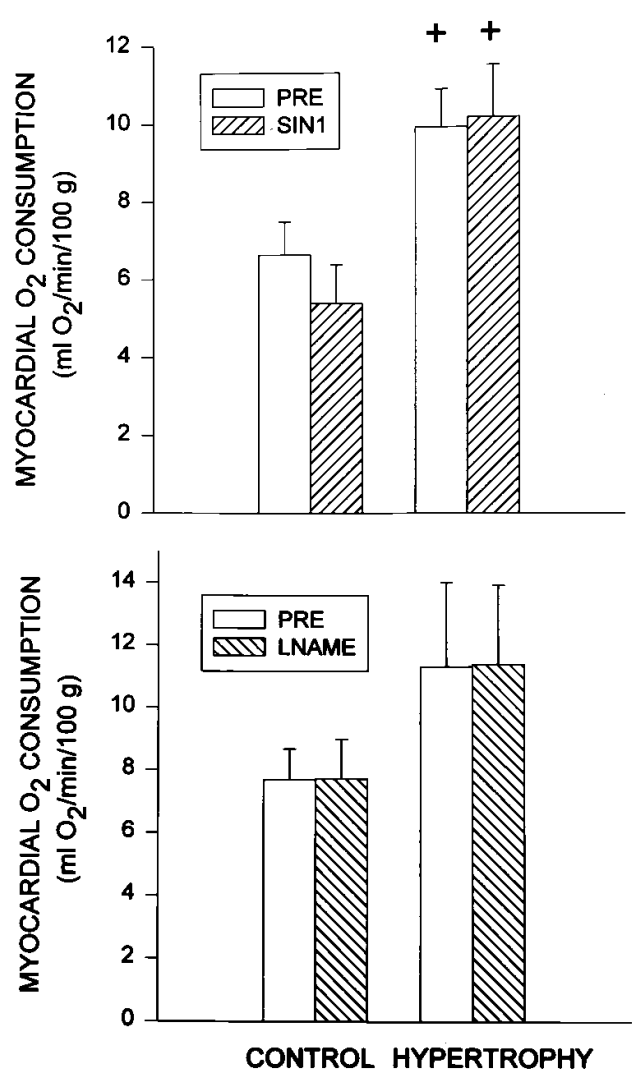

Figure 2. Effect of SIN-1 (top) and L-NAME (bottom) on local $\mathrm{O}_{2}$ consumption of the LAD region of the left ventricular free wall of both control and aortic valve stenosis-induced cardiac hypertrophic dogs. + Significantly different from comparable period in the control group.

Fig. 3 illustrates the effects of intracoronary SIN-1 or L-NAME on local myocardial cyclic GMP levels in the LAD and CFX (control) regions. In all left ventricular hypertrophy animals (SIN-1 and L-NAME groups), baseline cyclic GMP levels were significantly elevated as compared with controls. In dogs receiving SIN-1 (Fig. 3, top), significant differences were observed. Control animals had an increase in cyclic GMP (in the LAD region only). The left ventricular hypertrophy dogs also had an increase in cyclic GMP after SIN-1 (in the LAD region only). The increase in cyclic GMP with SIN-1 was significantly greater in the left ventricular hypertrophic than control dogs. Only the treated (LAD) and not the control (CFX) regions showed the changes with SIN-1. In dogs receiving L-NAME, there were no effects on cyclic GMP levels in control or LAD regions. There were no significant differences in cyclic GMP levels in a comparison between the LAD and CFX regions after nitric oxide synthase blockade (Fig. 3, bottom).

Soluble guanylate cyclase activity was also determined in six control and six hypertrophic hearts. Fig. 4 shows the guanylate cyclase activity in control and left ventricular hypertrophy dogs as a function of stimulation with sodium nitroprusside. The results demonstrated increases in both the maximal activity and sensitivity of guanylate cyclase in left ventricular hypertrophy as compared to control animals. Maximal activity increased significantly from $10.1 \pm 2.9$ to $25.5 \pm 6.5 \mathrm{pmol} / \mathrm{mg}$ protein per min (control vs left ventricular hypertrophy) in response to nitroprusside stimulation. Sensitivity also signifi-
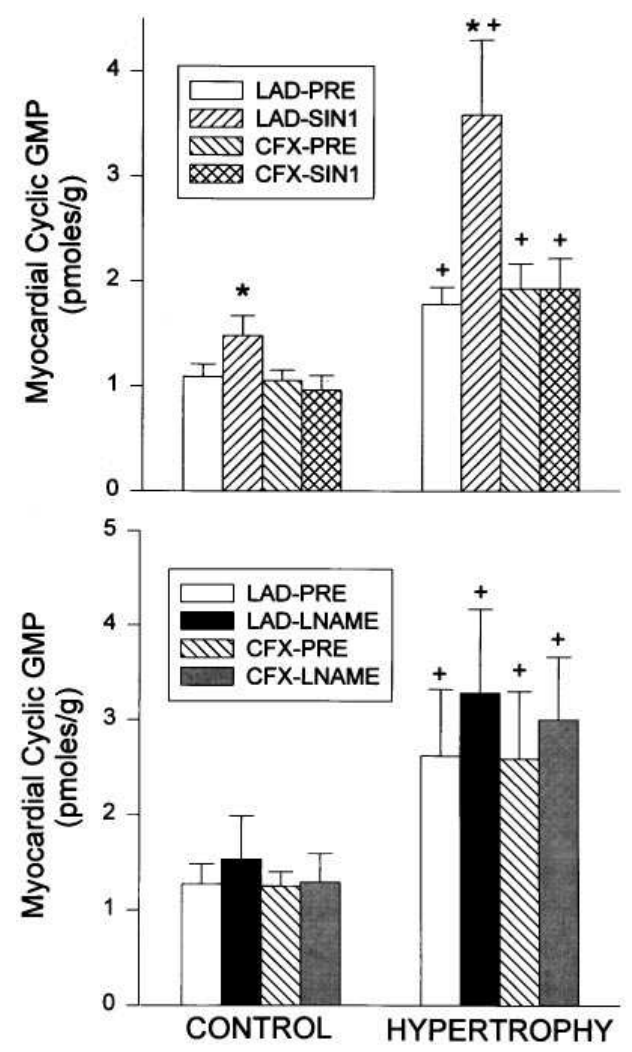

Figure 3. Effect of SIN-1 (top) and L-NAME (bottom) on cyclic GMP levels of the LAD and CFX regions of the left ventricular free wall. Data are presented for both control and aortic valve stenosisinduced cardiac hypertrophic dogs before ( $P R E)$ and during infusions of these agents. *Significantly different from control $(P R E)$ period. + Significantly different from comparable period in the control group.

cantly increased as indicated by a decrease in $\mathrm{EC}_{50}$ from $0.43 \pm 0.04$ to $0.28 \pm 0.04 \mathrm{mM}$ in left ventricular hypertrophic hearts. Cyclic GMP-phosphodiesterase activity was determined in 10 control and 10 hypertrophied hearts. There was no significant difference between the specific myocardial cyclic

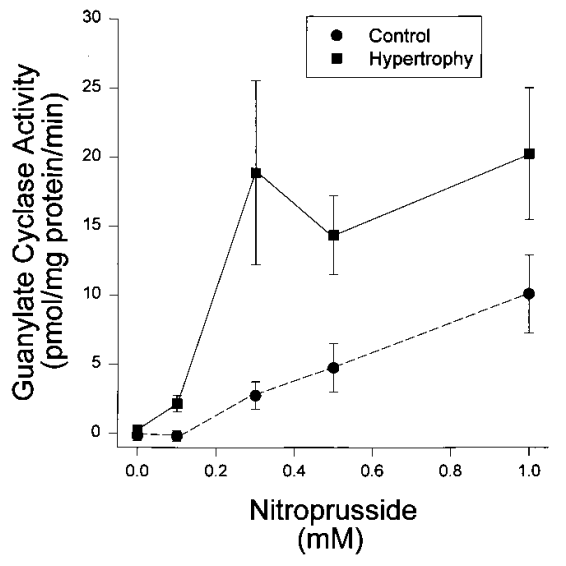

Figure 4. Soluble guanylate cyclase activity from both control and hypertrophy dogs. Guanylate cyclase activity was higher at all levels of stimulation with sodium nitroprusside. 
GMP-phosphodiesterase activity between control $(332 \pm 27$ $\mathrm{pmol} / \mathrm{mg}$ protein per min) and left ventricular hypertrophic $(335 \pm 56)$ hearts.

\section{Discussion}

The major finding of this study was that both basal and stimulated myocardial levels of cyclic GMP were enhanced in dogs with aortic valve-induced cardiac hypertrophy, and that this was related to increased myocardial guanylate cyclase activity. The lack of effect of blockade of nitric oxide synthase indicated that the increased cyclic GMP was not related to elevated basal production of nitric oxide. We stimulated guanylate cyclase via intracoronary injection of the nitric oxide donor 3-morpholino-sydnonimine (SIN-1), which increased cyclic GMP to a greater extent in the left ventricular hypertrophy than control dogs. The in vitro guanylate cyclase assay confirmed that both sensitivity and maximal activity were increased in left ventricular hypertrophy over controls. In left ventricular hypertrophy, this increased guanylate cyclase activity did not translate into a functional effect. Blockade of endogenous nitric oxide production via intracoronary injection of the arginine analog $N^{\mathrm{G}}$-nitro-L-arginine methyl ester (LNAME) was not associated with global hemodynamic, myocardial mechanical, myocardial cyclic GMP, or myocardial $\mathrm{O}_{2}$ consumption changes. Thus, it appears that increased guanylate cyclase activity and not increased endogenous basal NO production was associated with the increased baseline cyclic GMP seen in left ventricular hypertrophic animals.

Increases in cyclic GMP levels mediate smooth muscle relaxation in many tissues, including the coronary vessels $(10,12$, 16). Extrinsic organic nitrates and endogenous nitric oxide production lead to increased cyclic GMP levels in smooth muscle causing vasorelaxation $(11,12)$. SIN-1 is the active metabolite of the vasodilator molsidomine, which decomposes to release NO (21). We observed peripheral vasodilatation in our study as a result of intracoronary SIN-1, but local coronary blood flow did not increase, possibly related to its local functional and metabolic effects. In our study, we observed significant vasoconstriction as a direct result of inhibition of NO synthase with L-NAME. This was represented by the decreased LAD blood flow and increased local $\mathrm{O}_{2}$ extraction. We confirmed endothelial NO blockade by showing markedly decreased vasodilatation in response to acetylcholine after L-NAME. This blockade was also shown in a similar study by Smith and Canty (20).

In myocytes, altering cyclic GMP levels also appears to affect metabolism and function. Negative inotropic and metabolic responses have been demonstrated in response to guanylate cyclase stimulation in vitro $(1,4,15,28,29)$. The negative functional effects of cyclic GMP in cardiac muscle appear to be mediated by changes in calcium flux, resulting in quicker relaxation and shortened action potential duration $(1,3)$. We report decreasing myocardial function with increases in myocardial cyclic GMP. Previous studies from our laboratory and others have shown that stimulation of guanylate cyclase leads to negative in vivo myocardial inotropic effects $(1,2,30)$. Increasing myocyte cyclic GMP by inhibiting cyclic GMP-phosphodiesterase can also cause decreased myocardial $\mathrm{O}_{2}$ consumption (8). Other laboratories have also shown that increasing cyclic GMP leads to negative metabolic and inotropic effects on the myocardium $(3,4,29)$.
Basal cyclic GMP levels are markedly and consistently elevated in aortic valve stenosis-induced hypertrophic dog hearts $(2,7)$. Myocardial cyclic GMP levels have also been reported to be elevated in other types of pressure load hypertrophy (17). Cyclic GMP levels may also increase during some forms of heart failure $(18,19)$. However in the rat, myocardial cyclic GMP levels are normal after aortic constriction (31). In the rabbit, basal levels of myocardial cyclic GMP were not altered in thyroxine-induced hypertrophy (9). Cyclic GMP levels may be altered by changes in muscarinic receptors, nitric oxide synthase activity, atrial natriuretic hormone, guanylate cyclase activity, or by inhibiting the breakdown of cyclic GMP via cyclic GMP phosphodiesterase inhibition. We now report normal unaltered cyclic GMP-phosphodiesterase activity in this left ventricular hypertrophy model. We sought to test whether increased NO synthase or guanylate cyclase activities were responsible for the observed changes in cyclic GMP with left ventricular hypertrophy, and if this resulted in functional and/ or metabolic changes.

The level of cyclic GMP that we report is the average pool size in the left ventricular free wall. The free wall contains cardiac myocytes, endothelial cells, vascular smooth muscle, etc. Mammalian hearts, including dogs, consist of $\sim 80 \%$ cardiac myocytes, $10 \%$ vascular elements, and 10\% extra-myocyte space $(32,33)$. Much of the nonmyocyte space consists of vascular lumen and noncellular elements, which does not generate cyclic GMP. Most of the cyclic GMP that we measure comes from cardiac myocytes. Further, we have shown in isolated cardiac myocytes that SIN-1 causes similar changes in cyclic GMP leading to lowered myocyte metabolism (34). Thus, most of the measured changes in cyclic GMP must also be from cardiac myocytes.

The intracoronary infusion of the NO synthase blocker did not cause any significant changes in myocardial mechanics, regional myocardial $\mathrm{O}_{2}$ consumption, or myocardial cyclic GMP levels. We observed higher baseline levels of cyclic GMP in left ventricular hypertrophy animals, but NO synthase blockade did not change the baseline cyclic GMP levels in either left ventricular hypertrophy or control dogs. It had also been reported that NO synthase blockade did not alter local myocardial $\mathrm{O}_{2}$ consumption in the dog or pig heart $(13,14)$, although some effects have been observed in isolated hearts (35). We also confirmed blockade via the observed abolition of the vasodilatory effects of cholinergic stimulation after NO synthase blockade. We demonstrated that NO synthase blockade did not change baseline cyclic GMP levels in either control or left ventricular hypertrophic dogs given L-NAME. This implies that basal endogenous NO production is not sufficient to alter myocardial cyclic GMP levels, nor is it responsible for the elevated cyclic GMP levels found in cardiac hypertrophy.

All animals given SIN-1 showed increases in myocardial cyclic GMP. However, these increases were much greater in the animals with left ventricular hypertrophy. The guanylate cyclase assay showed that in left ventricular hypertrophy, both sensitivity and maximal activity of the enzyme were elevated. This could account for the different cyclic GMP levels seen in left ventricular hypertrophy dogs and for the greater increases in cyclic GMP in left ventricular hypertrophy after SIN-1. We did not examine the particulate guanylate cyclase activity or receptors such as atrial natriuretic peptide receptors, which could also alter cyclic GMP levels. Myocardial cyclic GMP levels have been reported to be elevated in other types of heart 
failure and hypertrophy (17-19). There have been reported changes in atrial natriuretic peptide receptors that affect cyclic GMP in cardiac hypertrophy (36). In addition, muscarinic receptors are affected by pressure load-induced hypertrophy in the dog (37). It is not clear whether increases in guanylate cyclase activity alone account for the increase in the level of myocardial cyclic GMP.

Control animals given SIN-1 showed an increase in cyclic GMP and the associated decrement in force and work. In left ventricular hypertrophy, cyclic GMP levels were greatly increased over their baseline, but this did not translate into functional changes. The reasons for the relative lack of functional effect as a result of the increased cyclic GMP in left ventricular hypertrophy are unknown. This differential functional response between control and hypertrophic myocardium to increased cyclic GMP has also been observed with the use of nitroprusside (2). Perhaps there is another modulator of the effects of cyclic GMP on the heart in dogs with left ventricular hypertrophy. Calcium sensitivity to the effect of cyclic GMP may be altered. There may also be differences in other effects of cyclic GMP, e.g. protein phosphorylation, in hypertrophied hearts. The myocardium of dogs with left ventricular hypertrophy may only respond to certain levels of cyclic GMP beyond which it demonstrates saturation kinetics (2). We do know that reducing cyclic GMP levels can increase local work in the hypertrophied dog heart (7).

In summary, we observed increased cyclic GMP in animals with left ventricular hypertrophy. An intracoronary SIN-1 injection caused significantly elevated cyclic GMP levels in both groups but there was a much greater increase in the left ventricular hypertrophy dogs. This was associated with decreased work and a downward trend in myocardial $\mathrm{O}_{2}$ consumption in control animals. There seems to be a lack of functional effects of cyclic GMP on the myocardium in these hypertrophied hearts. Nitric oxide synthase blockade led to no significant changes in global hemodynamics, cardiac mechanics, myocardial $\mathrm{O}_{2}$ consumption or myocardial cyclic GMP levels in either control or left ventricular hypertrophy animals. Thus, it appears that increased guanylate cyclase sensitivity and maximal activity and not nitric oxide is associated with the elevated levels of cyclic GMP seen in aortic valve stenosis-induced left ventricular hypertrophy.

\section{Acknowledgments}

The authors wish to thank Mr. Donald Thompson for his expert technical assistance.

This study was supported, in part, by United States Public Health System grant HL40320.

\section{References}

1. Lohmann, S.M., R. Fischmeister, and U. Walter. 1991. Signal transduction by cGMP in heart. Basic Res. Cardiol. 86:503-514.

2. Roitstein, A., J. Kedem, B. Cheinberg, H.R. Weiss, J. Tse, and P.M. Scholz. 1994. The effect of intracoronary nitroprusside on cyclic GMP and regional mechanics is altered in a canine model of left ventricular hypertrophy. $J$. Surg. Res. 57:584-590.

3. Sperelakis, N., N. Tohse, Y. Ohya, and H. Masuda. 1994. Cyclic GMP regulation of calcium slow channels in cardiac muscle and vascular smooth muscle cells. Adv. Pharmacol. 26:217-252.

4. Shah, A.M., H.A. Spurgeon, S.J. Sollott, A. Talo, and E.G. Lakatta. 1994. 8-bromo-cGMP reduces the myofilament response to $\mathrm{Ca}^{2+}$ in intact cardiac myocytes. Circ. Res. 74:970-978.

5. Paulus, W.J., P.J. Vantrimpont, and A.M. Shah. 1994. Acute effects of nitric oxide on left ventricular relaxation and diastolic distensibility in humans. Assessment of bicoronary sodium nitroprusside infusion. Circulation. 89:2070-2078.

6. Watanabe, A.M., and H.R. Besch, Jr. 1975. Interaction between cyclic adenosine monophosphate and cyclic guanosine monophosphate in guinea pig ventricular myocardium. Circ. Res. 37:309-317.

7. Guo, X., J. Kedem, A. Roitstein, J. Tse, P.M. Scholz, and H.R. Weiss 1994. Effect of intracoronary methylene blue on regional myocardial mechanics and cyclic GMP in experimental left ventricular hypertrophy (LVH). FASEB J. 8:310a. (Abstr.)

8. Weiss, H.R., E. Rodriguez, J. Tse, and P.M. Scholz. 1994. Effect of increased myocardial cyclic GMP induced by cyclic GMP-phosphodiesterase inhibition on oxygen consumption and supply of rabbit hearts. Clin. Exp. Pharm. Physiol. 21:607-614.

9. Weiss, H.R., E. Rodriguez, and J. Tse. 1995. Relationship between cGMP and myocardial $\mathrm{O}_{2}$ consumption is altered in $\mathrm{T}_{4}$-induced cardiac hypertrophy. Am. J. Physiol. 268:H686-H691.

10. Murad, F., V. Forstermann, M. Nakane, H. Schmidt, J. Pollock, H. Sheng, T. Matsumoto, T. Warner, J. Mitchell, R. Tracey, and W. Buechler. 1992. The nitric oxide-cGMP signal transduction pathway in vascular smooth muscle preparations and other tissues. Jpn. J. Pharmacol. 58(Suppl. 2):150-157.

11. Paulus, W.J. 1994. Endothelial control of vascular and myocardial function in heart failure. Cardiovasc. Drugs Ther. 8:437-446.

12. Schini, V.B., and P.M. Vanhoutte. 1993. Role of the L-arginine-nitric oxide pathway in vascular smooth muscle. Eur. Heart J. 14(Suppl. 1):16-21.

13. Gurevicius, J., M.R. Salem, A.A. Metwally, J.M. Silver, and G.J. Crystal. 1995. Contribution of nitric oxide to coronary vasodilation during hypercapnic acidosis. Am. J. Physiol. 268:H39-H47.

14. Kirkeboen, K.A., P.A. Naess, J. Offstad, and A. Ilebekk. 1994. Effects of regional inhibition of nitric oxide synthesis in intact porcine hearts. Am. J. Physiol. 266:H1516-H1527.

15. Brady, A.B., J.B. Warren, P. Poole-Wilson, T. Williams, and S.E. Harding. 1993. Nitric oxide attenuates cardiac myocyte contraction. Am. J. Physiol. 265:H176-H182.

16. Kelm, M., and J. Schrader. 1990. Control of coronary vascular tone by nitric oxide. Circ. Res. 66:1561-1575.

17. Nichols, J.R., and N.C. Gonzalez. 1982. Increase in myocardial cell cGMP concentration in pressure-induced myocardial hypertrophy. J. Mol. Cell. Cardiol. 14:181-183.

18. Jakob, G., J. Mair, M. Pichler, and B. Puschendorf. 1995. Ergometric testing and sensitivity of cyclic guanosine $3^{\prime}, 5^{\prime}$-monophosphate (cGMP) in diagnosing asymptomatic left ventricular dysfunction. B. Heart J. 73:145-150.

19. Michel, J.B., J.J. Mercadier, F.X. Galen, R. Urbain, J.C. Dussaule, M. Philippe, and P. Corvol. 1990. Urinary cyclic guanosine monophosphate as an indicator of experimental congestive heart failure in rats. Cardiovasc. Res. 24: 946-952.

20. Smith, T.P. Jr., and J.M. Canty, Jr. 1993. Modulation of coronary autoregulatory responses by nitric oxide: evidence for flow-dependent resistance adjustments in conscious dogs. Circ. Res. 73:232-240.

21. Wahler, G.M., and S.J. Dollinger. 1995. Nitric oxide donor SIN-1 inhibits mammalian cardiac calcium current through cGMP-dependent protein kinase. Am. J. Physiol. 268:C45-C54.

22. Scholz, P.M., M.E. Upsher, E. Eliades, J. Kedem, and H.R. Weiss. 1990 Alterations in the regional $\beta$-adrenergic system in experimental left ventricular hypertrophy. Cardiovasc. Res. 24:65-71.

23. Scholz, P.M., G.J. Grover, J.W. Mackenzie, and H.R. Weiss. 1990. Regional oxygen supply and consumption balance in experimental left ventricular hypertrophy. Basic Res. Cardiol. 85:575-584.

24. Scholz, P.M., W.C. Chiu, J. Kedem, and H.R. Weiss. 1993. Relationship between cyclic AMP content, regional myocardial function and $\mathrm{O}_{2}$ consumption in experimental left ventricular hypertrophy: effect of negative inotropes. Life Sci. 53:1847-1858.

25. Calderone, A., M. Bouvier, K. Li, C. Juneau, J. de Champlain, and J.-L. Rouleau. 1991. Dysfunction of the $\beta$ - and $\alpha$-adrenergic systems in a model of congestive heart failure. The pacing-overdrive dog. Circ. Res. 69:332-343.

26. Kimura, H., C.K. Mittal, and F. Murad. 1975. Activation of guanylate cyclase from rat liver and other tissues by sodium azide. J. Biol. Chem. 250: 8016-8022.

27. Tse, J., R. Wrenn, and J.F. Kuo. 1980. Thyroxine-induced changes in characteristics and activities of beta-adrenergic receptors and adenosine $3^{\prime}, 5^{\prime}$ monophosphate and guanosine $3^{\prime}: 5^{\prime}$-monophosphate systems in the heart may be related to reputed catecholamine supersensitivity in hyperthyroidism. Endocrinology. 107:6-16.

28. Wilkins, M.R., and P. Needleman. 1992. Effect of pharmacological manipulation of endogenous atriopeptin activity on renal function. Am. J. Physiol. 262:F161-F167.

29. Shah, A.M., and M.J. Lewis. 1992. Endothelial modulation of myocardial contraction: mechanisms and potential relevance in cardiac disease. Basic Res. Cardiol. 87(Suppl. 2):59-70.

30. Marczin, N., U.S. Ryan, and J.D. Catravas. 1992. Methylene blue inhibits nitrovasodilator and endothelium-derived relaxing factor-induced cyclic GMP accumulation in cultured pulmonary arterial smooth muscle cells via generation of superoxide anion. J. Pharm. Exp. Ther. 263:170-179. 
31. Dowell, R.T., J.L. Haithcoat, H.M. Thirkill, and W.K. Palmer. 1984. Heart cyclic nucleotide responses to sustained aortic constriction in neonatal and adult rats. Am. J. Physiol. 246:H197-H206.

32. Legato, M.J. 1979. Cellular mechanisms of normal growth in the mammalian heart. I. Qualitative and quantitative features of ventricular architecture in the dog from birth to five months of age. Circ. Res. 44:250-262.

33. Thompson, E.W. 1994. Quantitative analysis of myocardial structure in insulin-dependent diabetes mellitus: effects of immediate and delayed insulin replacement. Proc. Soc. Exp. Biol. Med. 205:294-305.

34. Gong, G.X., H.R. Weiss, and P.M. Scholz. 1996. Cyclic GMP decreases cardiac myocyte $\mathrm{O}_{2}$ consumption to a greater extent under conditions of in- creased metabolism. FASEB J. 10:314a. (Abstr.)

35. Grocott-Mason, R., P. Anning, H. Evans, M.J. Lewis, and A.M. Shah 1994. Modulation of left ventricular relaxation in isolated ejecting heart by endogenous nitric oxide. Am. J. Physiol. 267:H1804-H1813.

36. Brown, L.A., D.J. Nunez, and M.R. Wilkins. 1993. Differential regulation of natriuretic peptide receptor messenger RNAs during the development of cardiac hypertrophy in the rat. J. Clin. Invest. 92:2702-2712.

37. Vatner, D.E., D.L. Lee, K.R. Schwarz, J.P. Longabaugh, A.M. Fujii, S.F. Vatner, and C.J. Homcy. 1988. Impaired muscarinic receptor function in dogs with heart failure. J. Clin. Invest. 81:1836-1842. 